\title{
The 'happy puppet' syndrome of Angelman: review of the clinical features
}

\author{
S A ROBB, K R E POHL, M BARAITSER, J WILSON, AND E M BRETT \\ Hospital for Sick Children, Great Ormond Street, London
}

SUMmaRY Thirty six children with typical features of Angelman's syndrome, including global developmental delay, ataxia, episodes of paroxysmal laughter, seizures, and microcephaly were studied. The series included three sibships of three affected sisters, two affected brothers, and two affected sisters, respectively. The facial appearance is characterised by a prominent jaw, a wide mouth, and a pointed chin. Tongue thrusting is common. The movement disorder consists of a wide based, ataxic gait with frequent jerky limb movements and flapping of the hands. Tone is variable in the limbs with normal reflexes, and the plantar responses are usually flexor. The syndrome is being diagnosed more often, and attention is drawn to its diagnostic aspects.

In 1965 Angelman described a disorder affecting three unrelated, mentally subnormal children who had strikingly similar appearances, with unusual jerking movements, brachycephaly, protruding tongues, episodes of unprovoked laughter, and seizures. ${ }^{1}$ He remarked on the resemblance of this picture to that of a marionette and used the term 'puppet children' to describe the syndrome. Bower and Jeavons, ${ }^{2}$ describing two similar children, emphasised their happy demeanour and suggested that 'happy puppet' more aptly described the disorder. Further case reports followed, ${ }^{3-8}$ but their sporadic nature and small numbers suggested a rare syndrome. Though Williams and Frias suggested that the incidence may have been underestimated, ${ }^{9}$ fewer than 50 cases have so far been reported.

Since 1981 when Pampiglione ${ }^{10}$ drew attention to a number of unusual electroencephalographic features that had previously been described by Bower and Jeavons, ${ }^{2}$ we have identified 36 patients suffering from Angelman's syndrome at the Hospital for Sick Children, although the diagnosis was usually not made before referral. The correct diagnosis has assumed greater importance with the recent reports of familial cases ${ }^{11-14}$ suggesting that-rather than being sporadic - the syndrome may have genetic implications.

This report reviews the clinical features at diagnosis of our cases of Angelman's syndrome and by including three sets of siblings stresses the importance of genetic counselling.

\section{Patients and diagnostic criteria}

All patients fulfilled the following diagnostic criteria: delayed developmental milestones from early infancy; jerky ataxia; head circumference below the 50th centile for age; typical facial features with prominent lower jaw, wide mouth, and frequent tongue thrusting; happy disposition, often with episodes of paroxysmal or unprovoked laughter; and electroencephalographic features as described by Boyd et al..$^{15}$

Most of the patients had had seizures by the time of presentation, but these were not a prerequisite for the diagnosis. Thirty five of the patients were white and one was of east African Asian parentage. None of the parents was consanguineous. All patients were referred to the Departments of Neurology or Genetics at the Hospital for Sick Children for investigation of unexplained neurodevelopmental delay.

\section{Results}

The series comprised 18 boys and 18 girls aged between 18 months and 13 years 6 months at the time of diagnosis. There were three sets of siblings (three girls, two boys, and two girls); two sibling pairs have previously been reported. ${ }^{13}$ Pregnancy and delivery had usually been normal, with a mean birth weight for the group of $3060 \mathrm{~g}$. Subsequent growth had usually been normal; there was one boy 


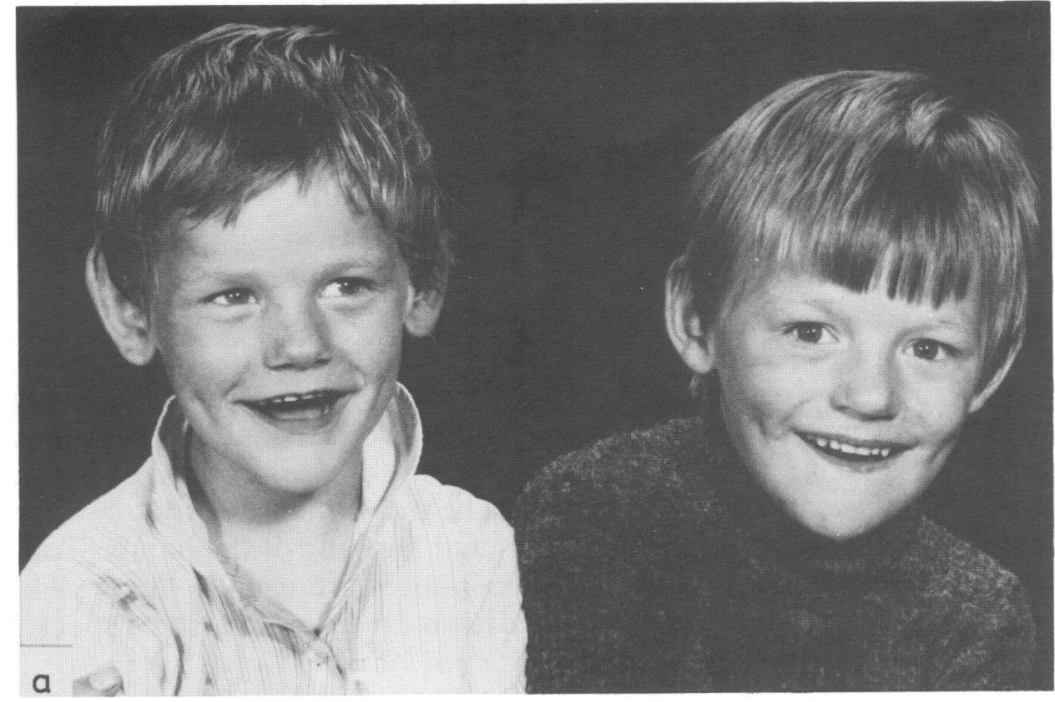

Figure Facial features of four typical patients from the series, including (a) two brothers with the condition.
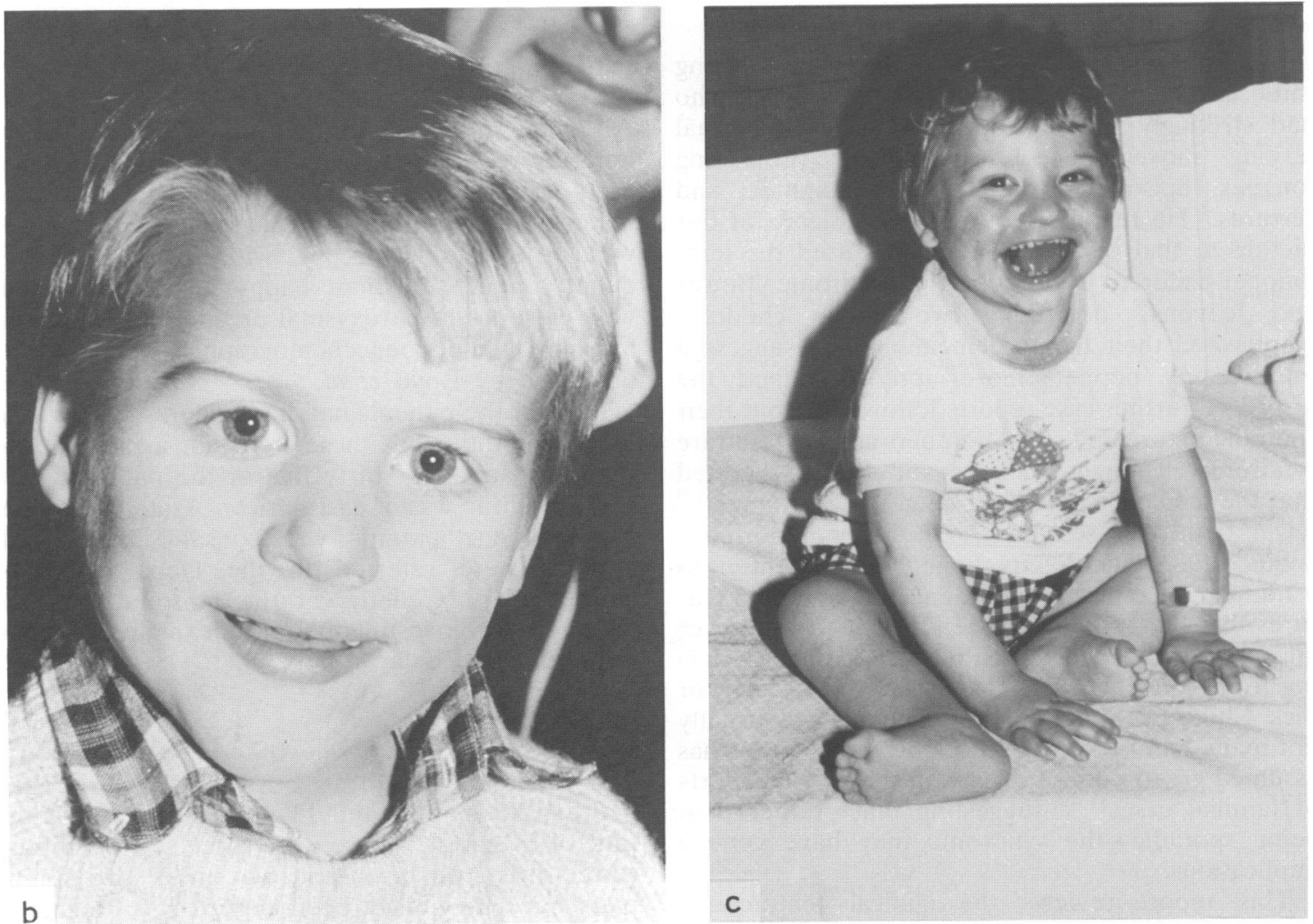

b 
aged 3 years 1 month whose height and weight were just below the third centile for no obvious reason. All children had delayed developmental milestones noted from infancy.

\section{FACIAL FEATURES}

The facial features though not pathognomic are highly suggestive, and are summarised in the table and shown in the figure. All patients had wide mouths, wide lower faces, rather prominent jaws, and pointed chins. Most had thin upper lips and bowed upper dentition that may have been caused by the frequent tongue thrusting.

Though most reports have stressed that these children have blonde hair and blue eyes, one third of

Table Main clinical features in 36 children with Angelman's syndrome

\begin{tabular}{|c|c|}
\hline & $\begin{array}{l}\text { No of } \\
\text { patients }\end{array}$ \\
\hline \multicolumn{2}{|l|}{ Sex: } \\
\hline Male & 18 \\
\hline Female & 18 \\
\hline Mental retardation & 36 \\
\hline \multicolumn{2}{|l|}{ Facial features: } \\
\hline Wide mouth & 36 \\
\hline Wide lower face & 36 \\
\hline Prominent jaw & 36 \\
\hline Pointed chin & 36 \\
\hline Thin upper lip & 32 \\
\hline Bowed teeth & 19 \\
\hline \multicolumn{2}{|l|}{ Colouring: } \\
\hline Blonde or red hair with blue eyes & 24 \\
\hline Other & 12 \\
\hline \multicolumn{2}{|l|}{ Head circumference: } \\
\hline Below second centile & 25 \\
\hline Second to 50th centile & 11 \\
\hline Seizures & 28 \\
\hline Jerky ataxia & 36 \\
\hline \multicolumn{2}{|l|}{ Walking: } \\
\hline Total & 25 \\
\hline Unaided & 18 \\
\hline Hands held & 7 \\
\hline \multicolumn{2}{|l|}{ Speech: } \\
\hline Less than three words & 7 \\
\hline More than three words & 0 \\
\hline \multicolumn{2}{|l|}{ Muscle tone: } \\
\hline Decreased & 7 \\
\hline Increased & 11 \\
\hline Normal & 18 \\
\hline \multicolumn{2}{|l|}{ Tendon reflexes: } \\
\hline Normal & 36 \\
\hline Abnormal & 0 \\
\hline \multicolumn{2}{|l|}{ Plantar responses: } \\
\hline Normal & 34 \\
\hline Equivocal & 2 \\
\hline \multicolumn{2}{|l|}{ Computed tomography: } \\
\hline Normal & 15 (of 23 ) \\
\hline Showed mild atrophy & 8 (of 23$)$ \\
\hline Electroencephalogram abnormal & 36 \\
\hline
\end{tabular}

our series were dark. Episodes of paroxysmal laughter are common, but may not always occur in infancy; some of our children (notably one child with severe gastro-oesophageal reflux) were miserable and difficult to manage as infants.

\section{AGE AT DIAGNOSIS}

There may be an evolution of facial features (as seen from earlier family photographs) so that below the age of one year (when the movement disorder is less obvious) clinical diagnosis may be difficult. The youngest age at diagnosis was 18 months. Twenty one cases $(58 \%)$ were diagnosed before the age of 5 years (median 2-3 years).

\section{SEIZURES}

Seizures were present at the time of diagnosis in 28 patients $(78 \%)$. The mean age of onset was 2 years, but most $(26,93 \%)$ had developed seizures by the age of 4 years. Of the eight patients who had not had seizures at the time of diagnosis, seven were aged 25 months or less; the remaining patient, a girl aged 13 years 6 months, fulfilled all other diagnostic criteria and also has a sister with Angelman's syndrome who had seizures.

\section{MENTAL HANDICAP}

All patients were severely mentally handicapped, with a particularly profound language deficit. Only seven patients could speak any words at all, and the maximum number was three.

\section{MOVEMENT DISORDER}

The movement disorder, present in all, consisted of a jerky ataxia affecting all limbs with a wide based gait and frequent flapping of the hands. Most children learned to walk though this was delayed, the earliest age at walking being 19 months. Twenty five patients $(69 \%)$ could walk at the time of diagnosis, most having walked between the ages of 2 and 3 years; of the 11 children who could not walk, six were still less than 2 years old and may walk later.

\section{NEUROLOGICAL SIGNS}

Twenty five of the patients (69\%) were microcephalic (head circumference below the second centile), and of the remainder none had a head circumference above the 50th centile for age. Muscle tone was variable being normal or slightly decreased below the age of 3 years; limb tone was mildly increased in 11 children, 10 of whom were aged over 3 years. Tendon reflexes were brisk in these children, but normal in the rest. Plantar responses were flexor in 34 and equivocal in two. 


\section{INVESTIGATIONS}

The electroencephalograms were abnormal in all patients, the abnormalities consisting of generalised, rather rhythmic intermediate slow waves at 4-6 cycles/second (c/s) and runs of 2-3 c/s activity anteriorly often with discharges. On closure of the eyes spikes with $2-4 \mathrm{c} / \mathrm{s}$ activity were seen posteriorly. Details of these changes are described elsewhere. ${ }^{15}$ Computed tomography of the brain was normal in 15 of the 23 patients examined and showed mild cerebral atrophy in eight. One of the scans also showed a small left temporal arachnoid cyst that was not considered to be of clinical importance.

The results of biochemical screening (including estimations of renal and hepatic function, and plasma ammonia and amino acid, urine amino acid, and organic acid concentrations) were normal, as were haematological measurements. After an interstitial deletion of 15q11-13 was detected in one child, reassessment of chromosome preparations from 10 further children showed four similar deletions. $^{16}$

\section{Conclusion}

The aim of this report was to draw attention to the diagnostic features of Angelman's syndrome, which may be recognised in children presenting with unexplained neurodevelopmental delay, and to point out that this condition (when specifically looked for) is commoner than has been hitherto thought. The combination of the facial features, profound retardation, ataxic movement disorder, seizures, and happy disposition strongly suggests the diagnosis and this may be confirmed by electroencephalographic analysis. The reports of familial cases both in this series and in other publications ${ }^{11-14}$ highlight the need for accurate recognition of the syndrome in order to be able to discuss the prognosis and management and to refer the parents for appropriate genetic counselling.
We thank Drs Ann Harden and Stewart Boyd for providing electroencephalographic data on the patients, and Dr Brian Kendall for reviewing the computed tomograms.

\section{References}

1 Angelman H. 'Puppet' children, a report on three cases. Dev Med Child Neurol 1965;7:681-8.

2 Bower BD, Jeavons PM. The 'happy puppet' syndrome. Arch Dis Child 1967;42:298-302.

${ }^{3}$ Berg JM, Pakula Z. Angelman's ('happy puppet') syndrome. Am J Dis Child 1972;123:72-4.

${ }^{4}$ Mayo O, Nelson OM, Townsend HRA. Three more 'happy puppets'. Dev Med Child Neurol 1973;15:63-74.

5 Moore JR, Jeavons PM. The 'happy puppet' syndrome: two new cases and a review of previous cases. Neuropadiatrie 1973;4: $172-9$.

${ }^{6}$ Elian M. Fourteen happy puppets. Clin Pediatr 1975;14:902-8.

7 Dooley JM, Berg JM, Pakula Z, MacGregor DL. The puppetlike syndrome of Angelman. Am J Dis Child 1981;135:621-4.

${ }^{8}$ Hersh JA, Bloom AS, Zimmerman AW, et al. Behavioural correlates in the happy puppet syndrome: a characteristic profile? Dev Med Child Neurol 1981;23:792-800.

9 Williams CA, Frias JL. The Angelman ('happy puppet') syndrome. Am J Med Genet 1982;11:453-60.

${ }^{10}$ Pampiglione G, Martinez A. Evolution of Angelman syndrome. Follow up of three new cases. Electroencephalogr Clin Neurophysiol 1983;56:72P.

11 Kurohi Y, Matsui I, Yamamoto Y. The 'happy puppet' syndrome in two siblings. Hum Genet 1982;56:227-9.

12 Pashayan HM, Singer W, Bove C, Eisenberg E, Seto B. The Angelman syndrome in two brothers. Am J Med Genet 1982;13:295-8.

13 Baraitser M, Patton MA, Lam STS, Brett EM, Wilson J. The Angelman (happy puppet) syndrome: is it autosomal recessive? Clin Genet 1987;31:323-30.

${ }^{14}$ Fisher JA, Burn J, Alexander FW, Gardner-Medwin D. Angelman (happy puppet) syndrome in a girl and her brother. J Med Genet 1987;24:294-8.

15 Boyd SG, Harden A, Patton MA. The EEG in early diagnosis of Angelman's (happy puppet) syndrome. Eur J Ped 1988;147: 503-13.

16 Pembrey M, Fennell J, van den Berghe J, et al. The association of Angelman syndrome and deletions within 15q11-13. J Med Genet 1988;25:274.

Correspondence to Dr SA Robb, Department of Neurology, Hospital for Sick Children, Great Ormond Street, London WC1N $3 \mathrm{JH}$.

Accepted 25 February 1988 